\title{
Contact allergy to local anaesthetics-value of patch testing with a caine mix in the baseline series
}

\author{
Ana Brinca, Rita Cabral and Margarida Gonçalo \\ Department of Dermatology, Coimbra University Hospital, 3000-075 Coimbra, Portugal \\ doi:10.1111/j.1600-0536.2012.02149.x
}

Summary

Background. Contact allergy to local anaesthetics is relatively common. Patch testing with benzocaine in the European baseline series is recommended for diagnosis, even though a caine mix has been previously suggested to be superior.

Objectives. To assess the frequency and patterns of contact allergy to local anaesthetics by using a caine mix (benzocaine, tetracaine, and cinchocaine) in the baseline series, and evaluate its efficiency as compared with benzocaine alone.

Methods. We reviewed the results of 2736 patch tests performed between 2000 and 2010 , identifying patients with positive reactions to caine mix or to one of seven local anaesthetics.

Results. One hundred and twelve patients (4.1\%) had at least one allergic reaction to local anaesthetics; 86 were tested with all seven local anaesthetics, resulting in 71 reactions in 53 patients. Cinchocaine gave the most reactions (50.7\%); these occurred as a single reaction in $83.3 \%$ of patients, mostly with current or past relevance $(97 \%)$. Benzocaine represented $22.5 \%$ of reactions, many of which were non-relevant $(44 \%)$ or resulting from cross-reactions with para-compounds.

Conclusions. Almost 70\% of allergic reactions to local anaesthetics would have been missed if benzocaine had been used as a screening allergen. This study supports a recommendation to replace benzocaine with a caine mix containing cinchocaine in the baseline patch test series.

Key words: benzocaine; caine mix; cinchocaine; cross-reactions; local anaesthetics; patch test reactivity.

Local anaesthetics derived from caines are widely used, mainly in injectable preparations, but also in topical preparations. Allergic contact dermatitis has frequently been reported following exposure to creams used for pruritus ani, haemorrhoids and insect bites, lotions for sunburn relief, and anaesthetic eye and auricular drops (1-4). Delayed hypersensitivity to caines used in local or locoregional anaesthesia is much rarer.

Correspondence: Ana Brinca, Department of Dermatology, Coimbra University Hospital, Praceta Dr Mota Pinto, 3000-075 Coimbra, Portugal. Tel: +351239400420; Fax: +351239400490. E-mail: anabrinca@gmail.com

Conflicts of interest: The authors have declared no conflicts.

Accepted for publication 19 June 2012
Caine molecules are structurally divided into three parts: a lipophilic (aromatic) group, an intermediate chain linkage, and a hydrophilic (amine) group (5, 6) (Fig. 1). Depending on their intermediate chain, they are usually classified into two major groups: esters and amides (Table 1) (6). Esters, which include benzocaine, procaine, tetracaine, and amilocaine, are metabolized by plasma esterases to $p$-aminobenzoic acid (PABA), which is considered to be responsible for the greater allergenic potential and cross-reactivity between anaesthetics in this group. Amide local anaesthetics, which include cinchocaine or dibucaine, lidocaine, bupivacaine, mepivacaine, and prilocaine, are not metabolized into the PABA metabolite, and are generally considered to have a lower allergenic potential $(5-12)$. Within this group, a subdivision into 
<smiles>CCOC(=O)c1ccc(N)cc1</smiles>

Ester local anaesthetic - Benzocaine<smiles>CCN(CC)CC(=O)Nc1c(C)cccc1C</smiles>

Amide local anaesthetic - Lidocaine<smiles>CCCCOc1cc(C(=O)NCCN(CC)CC)c2ccccc2n1</smiles>

Amide local anaesthetic- Cinchocaine

Fig. 1. Chemical structure of benzocaine (ester), cinchocaine and lidocaine (amides).

Table 1. Local anaesthetics used topically or for local anaesthesia (main synonyms)

\begin{tabular}{ll}
\hline Esters & \multicolumn{1}{c}{ Amides } \\
\hline Benzocaine & Articaine \\
Chloroprocaine & Bupivacaine \\
Cocaine & Bupivacaine \\
Procaine & Dibucaine/cinchocaine* \\
Proparacaine & Etidocaine \\
Tetracaine & Levobupivacaine \\
& Lidocaine \\
& Mepivacaine \\
& Prilocaine \\
& Ropivacaine \\
& Sameridine \\
& Tonicaine \\
\hline
\end{tabular}

*Considered by some as a separate group, an alkylamide (13). Adapted from Thyssen et al. (6).

alkylamides (cinchocaine) and acylamides (lidocaine) can also be considered (13).

At present, benzocaine is recommended within the European baseline series as a screening allergen to show contact allergy to local anaesthetics. Nevertheless, its efficacy has been repeatedly questioned since the 1980s (11, 14, 15). Several suggestions to use a caine mix (as used in the TRUE Test ${ }^{\circledR}(10)$ have not been fully accepted $(11,16)$, although this is the current practice in some countries, such as Portugal. Our study was aimed at clarifying the superiority of patch testing with a caine mix in the European baseline series, which includes two ester local anaesthetics and one amide local anaesthetic, over patch testing with the ester local anaesthetic benzocaine alone.

\section{Material and Methods}

Between 1 January 2000 and 31 December 2010, we sequentially patch tested 2736 patients with a mean age of $43.9 \pm 16$ years (M, 29.5\%; O, 23.5\%; A, $24.3 \%$; H, 37.9\%; L, 6.8\%; F, 26.1\%; A, 52.4\%). They underwent patch testing with the Portuguese baseline series, a modified European baseline series that includes a caine mix at $10 \%$ in petrolatum (benzocaine 5\% pet., tetracaine $2.5 \%$ pet., and cinchocaine $2.5 \%$ pet.; Chemotechnique Diagnostics, Vellinge, Sweden) instead of benzocaine.

Forty-six patients with a clinical history of contact dermatitis who might have used local anaesthetics, mainly with anogenital dermatitis or in an occupational setting, and 4 patients previously studied in the allergy department because of a localized oedema of the oral mucosa within $24 \mathrm{hr}$ of a consultation with a dentist and who had negative test results, were simultaneously patch tested, on their first visit, with a series of local anaesthetics that included benzocaine $5 \%$ pet., tetracaine $5 \%$ pet., procaine $1 \%$ pet., amilocaine $5 \%$ pet., lidocaine $5 \%$ pet., cinchocaine $5 \%$ pet., and prilocaine $5 \%$ pet. (Chemotechnique Diagnostics). All caine mix-positive patients were offered further testing with the same series of local anaesthetics.

Patch tests were applied on the upper back for 2 days with Finn Chambers ${ }^{\circledR}$ on Scanpor ${ }^{\circledR}$ tape (Epitest Ltd., Oy, Finland). Readings were performed at D2 and D3 or D4, according to International Contact Dermatitis Research Group guidelines (17), with advice for a referral reading at D7 in case of a late reaction.

Patients with positive reactions ( $1+$ or more intense) to the caine mix or to any of the separate allergens were evaluated with regard to age, sex, dermatosis location, positive reactions to chemicals of the para-group tested in the baseline series, namely $p$-phenylenediamine (PPD), $N$-isopropyl- $N^{\prime}$-phenyl- $p$-phenylenediamine and parabens, and relevance of positive reactions based on medical history. 
Table 2. Prevalence of positive reactions to local anaesthetics, with a total number of 71 positive reactions occurring in 53 patients

\begin{tabular}{|c|c|c|c|c|c|c|}
\hline & \multicolumn{2}{|c|}{ Number of positive reactions $(n=71)$} & \multicolumn{2}{|c|}{ One positive reaction $(n=41,77.4 \%)$} & \multicolumn{2}{|c|}{$\geq 2$ positive reactions $(n=12,22.6 \%)$} \\
\hline & $\mathrm{n}$ & $\%\left(n / n_{\text {total }}\right)$ & $\mathrm{n}$ & $\%\left(n / n_{\text {total }}\right)$ & $\mathrm{n}$ & $\%\left(n / n_{\text {total }}\right)$ \\
\hline Cinchocaine & 36 & 50.7 & 30 & 56.6 & 6 & 11.3 \\
\hline Benzocaine & 16 & 22.5 & 7 & 13.2 & 9 & 17 \\
\hline Tetracaine & 8 & 11.3 & 1 & 1.9 & 7 & 13.2 \\
\hline Procaine & 6 & 8.4 & 1 & 1.9 & 5 & 9.4 \\
\hline Lidocaine & 3 & 4.2 & 1 & 1.9 & 2 & 3.8 \\
\hline Amilocaine & 2 & 2.8 & 1 & 1.9 & 0 & 0 \\
\hline Prilocaine & 0 & - & 0 & 0 & 0 & 0 \\
\hline
\end{tabular}

\section{Results}

Of the 2736 patients, 110 reacted to the caine mix in the baseline series $(4.0 \%)$, and 2 additional patients reacted to cinchocaine during aimed testing. In total, 112 patients (35 males and 77 females, mean age $49.7 \pm 15.1$ years) had at least one allergic reaction to local anaesthetics, representing $4.1 \%$ of the whole population.

Of these patients, only 86 (25 males and 61 females, mean age $49.3 \pm 15.1$ years) were patch tested with all seven separate local anaesthetics; 84 reacted to the caine mix, and 2 were caine mix-negative but reacted to cinchocaine.

In $39.3 \%$ of caine mix-positive patients, local anaesthetics tested separately gave negative results, in 52\% of those with a $1+$ reaction and $48 \%$ with a $2+$ or $3+$ reaction. Fifty-three patients (15 males and 38 females, mean age $51.1 \pm 15.3$ years) had positive patch test reactions to separate local anaesthetics (61.6\%). Forty-one (77.4\%) reacted only to one local anaesthetic, and $12(22.6 \%)$ had two or more positive reactions, corresponding to a total of 71 positive reactions (Table 2).

Reactions to cinchocaine were most common (36/71, $50.7 \%)$, followed by reactions to benzocaine $(16 / 71$, $22.5 \%$ ), tetracaine, procaine, lidocaine, amilocaine, and prilocaine (Table 2). Most reactions to cinchocaine were isolated $(30 / 36,83.3 \%)$, whereas more than half of benzocaine-reactive patients $(9 / 16), 7$ of 8 of tetracainereactive patients and 5 of 6 of procaine-reactive patients showed reactivity to other local anaesthetics (Table 2).

Concerning reactivity to the different chemical groups (Tables 3 and 4), 14 patients reacted only to esters (26.4\%), 31 only to amides ( $58.5 \%)$, and 8 to both groups (15.1\%) (Table 5).

Reactivity to chemicals of the para-group (Table 6) was observed in 8 of 53 patients (15.1\%), 7 of them with reactivity to benzocaine and/or other ester local anaesthetics. One patient with contact dermatitis caused by a temporary henna tattoo also reacted to an amide local anaesthetic, cinchocaine. One patient with anogenital dermatitis caused by cinchocaine in an

Table 3. Reactivity only to ester local anaesthetics

\begin{tabular}{|c|c|c|c|c|c|c|c|c|}
\hline & \multicolumn{8}{|c|}{ Reactivity to esters only $(n=14)$} \\
\hline & Age (years) & Sex & Benzocaine & Tetracaine & Procaine & Amilocaine & Relevance & Presentation \\
\hline 1 & 54 & $\mathrm{~F}$ & + & - & + & NA & Cross-reaction & Eyelids \\
\hline 2 & 20 & $\mathrm{~F}$ & + & + & + & NA & Cross-reaction & Face \\
\hline 3 & 56 & $\mathrm{~F}$ & + & - & - & NA & Past & Lips \\
\hline 4 & 22 & $\mathrm{~F}$ & + & - & - & - & No & Eyelids \\
\hline 5 & 72 & $\mathrm{~F}$ & + & + & - & NA & Past & Leg ulcer \\
\hline 6 & 27 & $\mathrm{~F}$ & + & - & - & NA & No & Generalized \\
\hline 7 & 49 & M & + & - & - & - & Past & Trunk \\
\hline 8 & 47 & $\mathrm{~F}$ & - & + & - & - & Past & Hand \\
\hline 9 & 40 & $\mathrm{~F}$ & + & - & - & - & Cross-reaction & Hand \\
\hline 10 & 53 & $\mathrm{~F}$ & + & - & + & - & Past & Extremity \\
\hline 11 & 78 & $\mathrm{~F}$ & - & - & + & - & Cross-reaction & Eyelids \\
\hline 12 & 51 & $\mathrm{~F}$ & + & - & - & - & Past & Generalized \\
\hline 13 & 52 & $\mathrm{~F}$ & - & - & - & + & Past & Eyelids \\
\hline 14 & 14 & $\mathrm{~F}$ & + & - & - & - & Cross-reaction & Tattoo \\
\hline
\end{tabular}

+, positive; -, negative; F, female; M, male; NA, not applicable. 
Table 4. Reactivity only to amide local anaesthetics

\begin{tabular}{|c|c|c|c|c|c|c|c|}
\hline & & & & tivity to amides & $=31)$ & & \\
\hline & Age (years) & Sex & Lidocaine & Cinchocaine & Prilocaine & Relevance & Presentation \\
\hline 1 & 52 & $\mathrm{~F}$ & - & + & NA & Current & Anogenital \\
\hline 2 & 51 & M & - & + & - & Current & Anogenital \\
\hline 3 & 65 & M & - & + & - & Past & Hand \\
\hline 4 & 49 & M & - & + & - & Current & Anogenital \\
\hline 5 & 25 & $\mathrm{~F}$ & - & + & - & Past & Hand \\
\hline 6 & 72 & $\mathrm{~F}$ & - & + & - & Current & Anogenital \\
\hline 7 & 58 & $\mathrm{~F}$ & - & + & - & Current & Anogenital \\
\hline 8 & 53 & $\mathrm{~F}$ & - & + & - & Past & Immediate HS \\
\hline 9 & 51 & M & - & + & - & Current & Anogenital \\
\hline 10 & 60 & $\mathrm{~F}$ & - & + & - & Current & Anogenital \\
\hline 11 & 42 & M & - & + & - & Past & Hand \\
\hline 12 & 59 & $\mathrm{~F}$ & - & + & - & Past & Lips \\
\hline 13 & 72 & $\mathrm{~F}$ & - & + & - & Past & Trunk \\
\hline 14 & 62 & $\mathrm{~F}$ & - & + & - & Past & Immediate HS \\
\hline 15 & 35 & $\mathrm{~F}$ & + & - & NA & No & Lips \\
\hline 16 & 36 & $\mathrm{~F}$ & - & + & - & Past & Immediate HS \\
\hline 17 & 57 & $\mathrm{~F}$ & - & + & - & Current & Anogenital \\
\hline 18 & 54 & $\mathrm{~F}$ & - & + & - & Current & Anogenital \\
\hline 19 & 73 & $\mathrm{~F}$ & - & + & - & Past & Eyelid \\
\hline 20 & 32 & M & - & + & - & Current & Anogenital \\
\hline 21 & 56 & $\mathrm{~F}$ & - & + & - & Past & Immediate HS \\
\hline 22 & 77 & $\mathrm{~F}$ & - & + & - & Past & Generalized \\
\hline 23 & 60 & M & - & + & - & Past & Generalized \\
\hline 24 & 43 & M & - & + & - & Current & Anogenital \\
\hline 25 & 44 & $\mathrm{~F}$ & - & + & - & Current & Eyelids \\
\hline 26 & 73 & $\mathrm{~F}$ & - & + & - & Past & Leg \\
\hline 27 & 57 & M & - & + & - & Current & Anogenital \\
\hline 28 & 50 & M & - & + & - & Current & Anogenital \\
\hline 29 & 66 & $\mathrm{~F}$ & - & + & - & Past & Penicillin HS \\
\hline 30 & 45 & $\mathrm{~F}$ & - & + & - & Past & Penicillin HS \\
\hline 31 & 28 & $\mathrm{~F}$ & - & + & - & Past & Hand \\
\hline
\end{tabular}

+, positive; -, negative; F, female; HS, hypersensitivity; M, male; NA, not applicable.

Table 5. Reactivity to both ester and amide local anaesthetics

\begin{tabular}{|c|c|c|c|c|c|c|c|c|c|}
\hline & \multicolumn{9}{|c|}{ Reactivity to both esters and amides $(n=8)$} \\
\hline & \multicolumn{4}{|c|}{ Ester } & \multicolumn{3}{|c|}{ Amide } & \multirow[b]{2}{*}{ Relevance } & \multirow[b]{2}{*}{ Presentation } \\
\hline & 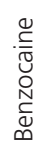 & 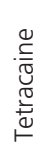 & 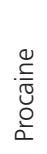 & 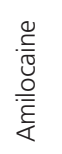 & 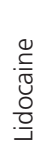 & 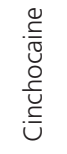 & 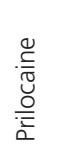 & & \\
\hline 1 & - & + & - & NA & - & + & NA & Past & Hand \\
\hline 2 & - & + & - & NA & - & + & NA & Current & Anogenital \\
\hline 3 & + & + & + & NA & - & + & NA & Cross-reaction & Tattoo \\
\hline 4 & + & - & - & - & + & - & - & Past & Face \\
\hline 5 & + & + & + & + & + & NA & NA & Past & Generalized \\
\hline 6 & + & - & - & - & - & + & - & Current & Anogenital \\
\hline 7 & - & + & - & - & - & + & - & Current & Anogenital \\
\hline 8 & + & - & - & - & - & + & - & Current & Generalized \\
\hline
\end{tabular}

+, positive; -, negative; NA, not applicable. 
Table 6. Cross-reactivity between local anaesthetics and para-group compounds

\begin{tabular}{|c|c|c|c|c|c|c|c|c|c|c|c|c|}
\hline & \multicolumn{12}{|c|}{ Cross-reactivity between local anaesthetics and para-group compounds $(\mathrm{n}=8)$} \\
\hline & \multicolumn{4}{|c|}{ Ester } & \multicolumn{3}{|c|}{ Amide } & \multicolumn{3}{|c|}{ Para group } & \multirow[b]{2}{*}{ Relevance } & \multirow[b]{2}{*}{ Presentation } \\
\hline & 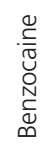 & 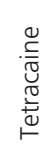 & 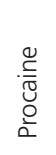 & 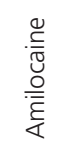 & 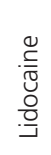 & 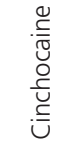 & 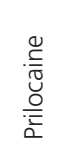 & 음 & $\begin{array}{l}\frac{n}{d} \\
\frac{0}{0} \\
\frac{0}{\sigma} \\
\alpha\end{array}$ & $\frac{0}{\underline{a}}$ & & \\
\hline 1 & + & - & + & NA & - & - & NA & + & - & - & Cross-reaction & Eyelids \\
\hline 2 & + & + & + & NA & - & - & NA & + & - & - & Cross-reaction & Face \\
\hline 3 & + & + & + & NA & - & + & NA & + & + & - & Cross-reaction & Tattoo \\
\hline 4 & + & - & - & - & - & NA & - & + & - & - & Cross-reaction & Hand \\
\hline 5 & + & - & + & - & - & NA & - & + & - & - & Past & Leg \\
\hline 6 & - & - & + & - & - & - & - & + & - & - & Cross-reaction & Eyelid \\
\hline 7 & + & - & - & - & - & - & - & + & - & + & Cross-reaction & Tattoo \\
\hline 8 & - & - & - & NA & - & + & NA & + & - & - & Current & Anogenital \\
\hline
\end{tabular}

+, positive; -, negative; IPPD, $N$-isopropyl- $N^{\prime}$-phenyl-p-phenylenediamine; NA, not applicable; PPD, $p$-phenylenediamine.

anti-haemorrhoid ointment had a positive PPD allergy, a probable concomitant reaction with relevance to previous hair dye allergy.

Among the 53 patients with positive reactions to at least one anaesthetic, $44(83 \%)$ were considered to be relevant, 19 (35.8\%) of which with current relevance. Anogenital dermatitis was the primary site of involvement in 16 patients $(30.2 \%)$. Previous exposure to local anaesthetics with past relevance was considered in 25 patients $(47.2 \%)$ who were patch tested for other reasons, mainly because of hand eczema.

On comparison of the relevance of cinchocaine and benzocaine reactions, 35 of cinchocaine reactions $(97.2 \%)$ were relevant, whereas relevance could be suspected in only 9 of 16 benzocaine-allergic patients $(56.2 \%)$, with many reactions being explained by crossreactivity with PPD in henna tattoos or hair dye allergy (3).

In the group of 53 patients with allergy to at least one anaesthetic, 37 did not react to benzocaine (69.8\%). Thus, contact allergy to local anaesthetics would not have been diagnosed or suspected if benzocaine were the only anaesthetic tested in the baseline series, whereas only 2 of 112 patients would have been missed with use of the caine mix (1.8\%).

\section{Discussion}

The $4.0 \%$ prevalence of caine mix reactivity reported here is higher than in other studies, namely those of Beck and Holden (11), with 84 of 3000 patients positive (2.8\%) and Sidhu et al. (16), with 91 of 5464 patients positive $(1.7 \%)$, both using the same caine mix, and Wilkinson et al. (18), with 26 of 1981 patients positive (1.3\%), using a caine mix with higher concentrations (15\% and 25\%).
Cinchocaine (dibucaine), which is included in the amide group that is considered to be less allergenic, was the main agent responsible for contact allergy to local anaesthetics, and so it seems to be very useful for screening for contact allergy to local anaesthetics. This is in line with recent studies in the United Kingdom and Finland $(16,18,19)$, but in contrast to older reports, where benzocaine reactivity was most prevalent $(11,20)$, namely in the United Kingdom, where it represented $47.5 \%$ of positive reactions to local anaesthetics by the end of the 1980s (11). Availability and prescription habits are different between countries and are continuously changing over time, which may explain the high variability of results across the world. The anti-haemorrhoid topical treatments that are frequently used contain mainly cinchocaine, as the over-the-counter ointments Faktu ${ }^{\circledR}$ and Nupercainal ${ }^{\circledR}$, and Scheriproct ${ }^{\circledR}$ ointment, which requires a medical prescription. Others contain tetracaine (Hemofissural ${ }^{\circledR}$ or lidocaine (Doxiproct ${ }^{\circledR}$ and Ultraproct ${ }^{\circledR}$. Two patients presented with a generalized dermatitis caused by cinchocaine, probably related to systemic absorption through the rectal mucosa, as reported elsewhere $(21,22)$.

Over $75 \%$ of patients reacted to a single local anaesthetic, in accordance with other studies $(11,20)$. Of the patients reacting to multiple local anaesthetics, $66.7 \%$ reacted to both esters and amides, which is a lower proportion than in Warshaw's study (20). Within the ester group, reactivity to two or three local anaesthetics could be explained by cross-reactivity, owing to the chemical similarity of these molecules. Within the amide group, as in other reports, no simultaneous reactions were observed between cinchocaine and lidocaine (13, 23, 24), and cinchocaine-positive patients tolerated local 
anaesthesia with subcutaneous lidocaine, which may suggest that cinchocaine should be included in a separate subgroup within the amide local anaesthetics, as an alkylamide (13).

Simultaneous reactivity to cinchocaine or lidocaine and an ester-type local anaesthetic, similar to that previously reported $(15,19)$, may be a result of separate sensitization, because most of those patients have been exposed to multiple topical drugs. In 3 patients, we could not explain the simultaneous reactivity to ester and amide local anaesthetics.

Probable cross-reactivity between local anaesthetics and other chemicals with a para-group occurred in 8 patients, mainly within the group of benzocaine-allergic patients $(37.5 \%)$, in accordance with the $33 \%$ of cases reported by Thyssen et al. (14). In contrast, only 5.6\% of cinchocaine-allergic patients showed reaction to these chemicals.

Benzocaine was once regarded as a good indicator of local anaesthetic sensitization. Nowadays, however, it is rarely used by pharmaceutical companies, whereas cinchocaine is present in many over-the-counter anogenital preparations. Benzocaine induced positive reactions in a minority of patients $(18.6 \%), 44 \%$ of which were either not relevant or attributable to cross-reactions, suggesting, as in the study of Thyssen, that this allergen is not useful in the baseline series (14). In contrast, cinchocaine, the main allergen responsible for caine mix reactivity, was considered to be relevant in $97.2 \%$ of cases, mainly related to anti-haemorrhoid ointments. Adding cinchocaine to benzocaine in a mix allowed the diagnosis of contact allergy to local anesthetics in 37 additional patients, most of them with relevant reactions $(94.6 \%)$.

The caine mix used did not detect 2 patients with relevant reactions to cinchocaine probably because cinchocaine is tested separately at a higher concentration (5\% pet). Approximately $40 \%$ of caine mix-positive patients did not react to its constituents, which might suggest false-positive reactions, even though two were still considered to be relevant. We suggest that, after a caine mix positive reaction, it is highly recommended to test caines separately before advising patients concerning avoidance of local anaesthetics.

The present study, with a significant number of patients from a single centre, has the limitation that caine mix and benzocaine were not simultaneously tested in all patients. Nevertheless, these data have shown that the caine mix detected significantly more cases of relevant contact allergy to local anaesthetics than benzocaine. Some of these were unsuspected from the clinical history, and would have been missed if benzocaine was tested alone in the baseline series. Accordingly, a caine mix containing cinchocaine could, with benefit, replace benzocaine in the European baseline series, but a multicentre study involving several clinics in Europe simultaneously patch testing caine mix and benzocaine could strongly contribute to a definite recommendation to change the baseline series.

\section{References}

1 Fisher A A. Dermatitis due to benzocaine present in sunscreens containing glyceryl PABA (Escalol 106). Contact Dermatitis 1977: 3: 170-171.

2 Lewis F M, Harrington C I, Gawkrodger D J. Contact sensitivity in pruritus vulvae: a common and manageable problem. Contact Dermatitis 1994: 31: 264-265.

3 Lodi A, Ambonati M, Coassini A, Kouhdari Z, Palvarini M, Crosti C. Contact allergy to 'caines' caused by anti-hemorrhoidal ointments. Contact Dermatitis 1999: 41: 221-222.

4 van Ketel W G. Contact allergy to different antihaemorrhoidal anaesthetics. Contact Dermatitis 1983: 9: 512-513.

5 Altman R S, Smith-Coggins R, Ampel L L. Local anesthetics. Ann Emerg Med 1985: 14: 1209-1217.

6 Thyssen J P, Menné T, Elberling J, Plaschke P, Johansen J D. Hypersensitivity to local anaesthetics-update and proposal of evaluation algorithm. Contact Dermatitis 2008: 59: 69-78.
7 Eggleston S T, Lush L W. Understanding allergic reactions to local anesthetics. Ann Pharmacother 1996: 30: 851-857.

8 Carazo J L, Morera B S, Colom L P, Gálvez Lozano J M. Allergic contact dermatitis from ethyl chloride and benzocaine. Dermatitis 2009: 20: E13-E15.

9 Svedman C, Ekqvist S, Möller H, Björk J, Gruvberger B, Holmström E, Bruze M. Unexpected sensitization routes and general frequency of contact allergies in an elderly stented Swedish population. Contact Dermatitis 2007: 56: 338-343.

10 Kreilgård B, Hansen J, Fischer T. Chemical, pharmaceutical and clinical standardization of the TRUE Test caine mix. Contact Dermatitis 1989: 21: 23-27.

11 Beck M H, Holden A. Benzocaine-an unsatisfactory indicator of topical local anaesthetic sensitization for the UK. $\mathrm{Br}$ J Dermatol 1988: 118: 91-94.

12 Nettis E, Napoli G, Ferrannini A, Tursi A. The incremental challenge test in the diagnosis of adverse reactions to local anesthetics. Oral Surg Oral Med Oral Pathol Oral Radiol Endod 2001: 91: 402-405.

13 Kearney C R, Fewings J. Allergic contact dermatitis to cinchocaine. Australas J Dermatol 2001: 42: 118-119.

14 Thyssen J P, Engkilde K, Menné T, Johansen J D. Prevalence of benzocaine and lidocaine patch test sensitivity in Denmark: temporal trends and relevance. Contact Dermatitis 2011: 65: 76-80.

15 Ramirez P, Sendagorta E, Floristan U, Feltes R A, Vidaurrazaga C. Allergic contact dermatitis from antihemorrhoidal ointments: concomitant sensitization to both amide and ester local anesthetics. Dermatitis 2010: 21: 176-177.

16 Sidhu S K, Shaw S, Wilkinson J D. A 10-year retrospective study on benzocaine allergy in the United Kingdom. Am J Contact Dermat 1999: 10: 57-61.

17 Wilkinson D S, Fregert S, Magnusson B et al. Terminology of contact dermatitis. Acta Derm Venereol 1970: 50: 287-292. 
18 Wilkinson J D, Andersen K E, Lahti A, Rycroft R J, Shaw S, White I R.

Preliminary patch testing with $25 \%$ and 15\% 'caine'-mixes. The EECDRG. Contact Dermatitis 1990: 22: 244-245.

19 Jussi L, Lammintausta K. Sources of sensitization, cross-reactions, and occupational sensitization to topical anaesthetics among general dermatology patients. Contact Dermatitis 2009: 60: $150-154$.
20 Warshaw E M, Schram S E, Belsito D V et al. Patch-test reactions to topical anesthetics: retrospective analysis of cross-sectional data, 2001 to 2004. Dermatitis 2008: 19: 81-85.

21 Erdmann S M, Sachs B, Merk H F. Systemic contact dermatitis from cinchocaine. Contact Dermatitis 2001: 44: 260-261.

22 Marques C, Faria E, Machado A, Gonçalo $\mathrm{M}$, Gonçalo S. Allergic contact dermatitis and systemic contact dermatitis from cinchocaine. Contact Dermatitis 1995: 33: 443.

23 González Mahave I, Lobera T, Blasco A, Del Pozo M D. Allergic contact dermatitis caused by cinchocaine. Contact Dermatitis 2008: 58: 55-58.

24 Weightman W, Turner T. Allergic contact dermatitis from lignocaine: report of 29 cases and review of the literature. Contact Dermatitis 1998: 39: 265-266. 